\title{
SISTEM PENGAJARAN BAHASA ARAB MODERN UNTUK NON -ARAB
}

\author{
Maria Ulfa \\ Universitas Islam Jember \\ E-mail:
}

\begin{abstract}
Abstrack
One of the fundamental weaknesses of Arabic language teaching system in non-Arab circles, especially in Indonesia, is the weakness of the teaching curriculum that is applied. In all its aspects, especially the vision and methodology, the existing curriculum generally teaches Arabic with a traditional orientation, ie for religious purposes with accentuation on aspects of grammar mastery and translation skills. For the present time, the teaching system with such curriculum model is no longer relevant and therefore must be in the fox immediately. Because, when referring to the development of today's Arabic language as an international language is no longer only functioning as a religious language. But it has become a medium of communication all aspects of life. Consequently, Arabic is no longer sufficient to be mastered only passively in the form of grammar mastery and translation skills, but must be communicated in a broader sense, both spoken and written. Therefore, the Arabic language teaching system has been developed with a modern oriented teaching curriculum. It is a well-designed curriculum with complete content and elements as a teaching system as well as teaching Arabic language for the purpose of supporting its role in today's day.
\end{abstract}

Keyword: System, Teaching Arabic, Modern, Non-Arabic

\begin{abstract}
Abstrak
Salah satu kelemahan mendasar system pengajaran bahasa arab di kalangan non arab terutama di Indonesia, adalah lemahnya kurikulum pengajaran yang di terapkan. Dalam segenap aspeknya, terutama visi dan metodologi, kurikulum yang ada pada umumnya mengajarka bahasa arab dengan orientasi tradisional, yakni demi tujuan keagamaan dengan aksentuasi pada aspek penguasaan
\end{abstract}


grammar dan keahlian menterjemah. Untuk masa sekarang ini, system pengajaran dengan model kurikulum seperti ini tidak lagi relevan dan oleh karenanya harus segera di rubah. Sebab, kalau merujuk pada perkembangan dewasa ini bahasa arab sebagai bahasa internasional tidak lagi hanya berfungsi sebatas bahasa agama. Akan tetapi telah menjadi media komunikasi seluruh aspek kehidupan. Konsekuensinya, bahasa arab tidak lagi cukup hanya dikuasai secara pasif dalam bentuk penguasaan grammar dan keahlian menterjemah, akan tetapi harus dikuasai secara komunikatif dalam pengertian yang lebih luas, baik lisan maupun tulisan. Oleh karenanya, system pengajaran bahasa arab sudah saatnya dikembangkan dengan kurikulum pengajaran yang berorientasi modern. Yakni kurikulum yang dirancang dengan muatan dan unsure- unsure yang lengkap sebagai sebuah system pengajaran sertamengarahkan pengajaran bahasa arab untuk tujuan yang mendukung perannya dizaman sekarang ini.

Katakunci: System, Pengajaran Bahasa Arab, Modern, Non - Arab

\section{A. Pendahuluan}

Salah satu persoalan mendasar dalam system pengajaran bahasa arab untuk non- arab adalah lemahnya kurikulum yang diterapkan, terutama dari segi materi dan metodologi pengajaran. Sejumlah riset ilmiah menunjukkan bahwa semangat mempelajari bahasa arab yang cenderung meningkat di sejumlah Negara non- arab belum di dukung oleh kurikulum pengajaran yang modern sehingga hasil yang di capai pun masih jauh dari harapan . diantara persoalan yang menjadi sebab lemahnya kurikulum pengajaran tersebut adalah belum adanya buku ajar atau buku pegangan yang memadai sebagai materi pengajaran, serta minimnya dukungan tanaga pengajar yang memiliki kualifikasi yang memadai sebagai guru bahasa arab. ${ }^{1}$

Buku - buku yang di jadikan pegangan pengajaran bahasa arab pada umumnya adalah buku- buku materi bahasa arab, seperti buku nahwu, sharaf, insya', balaghoh, serta buku- buku materi keagamaan yang di tulis dalam bahasa arab yang sebenarnya tidak dirancang untuk pengajaran bahasa. Buku- buku ini tidak akan mendukung pengajaran bahasa yang

1 Rusdi Ahmad Tu'aimah,ta'lim al lughoh al- arabiyah lighairi natiqina biha: manahijuhu wa asalibuhu, manshurat al- munazamat al-islamiyah li at-tarbiyah wa al ulum wa ath-staqofah, rabat $1989: 5$ 
efektif, karena pada dasarnya di susun tidak atas dasar prisip- prisip pendidikan dan pengajaran bahasa.

Disamping tidak di dukung oleh buku dan materi pengajaran yang ideal, kurikulum pengajaran bahasa arab juga belum didukung oleh guruguru dan tenaga pengajar dengan kualifikasi yang memedai. Guru-guru dan pengajar bahasa arab pada umumnya adalah mereka yang di pilih dengan kualifikasi longgar, mengetahui bahasa arab tanpa harus mengetahui cara pengajarannya. Padahal, dalam dunia pengajaran bahasa di bedakan dengan sangat ketat antara ahli bahasa dengan ahli pengajaran bahasa, sebagaimana di bedakan antara buku tentang bahasa dan buku tentang pengajaran bahasa. Seorang ahli bahasa tidak serta merta bisa mengajarkan bahasa yang dikuasainya. Aktifitas pengajaran bahasa menurut keahlian dan pengetahuan khusus yang tidak hanya membutuhkan penguasaan materi, tapi juga bagaimana mengajarkan materi tersebut atas dasar prinsipprinsip tertentu dalam sebuah proses belajar mengajar.

Lebih jauh, pengajaran bahasa arab untuk non - arab juga tidak dirancang dengan baik, diantaranya dari segi tujuan pengajaran yang masih sangat tefokus pada aspek keagamaan, yakni pengajaran bahasa arab untuk memahami al- qur'an dan sunnah serta literature- literature berbahasa arab. Di samping itu, metode- metode pengajaran yang di pakai masih menganut pendekatan nahwu dan terjamah yang merupakan pendekatan atau tertua dalam sejarah pengajaran bahasa asing yang oleh beberapa riset terbukti tidak berhasil mengajarkan bahasa secara efektif. Dua kekurangan mendasar ini masih diperparah oleh silabus atau materi pengajaran bahasa arab yang tidak ideal. Silabus dan materi yang dipakai pada umumnya diadopsi dari kitab- kitab tertentu tanpa memperhatikan karakteristik materi bahasa arab itu sendiri serta tingkat kemampuan anak didik yang akan menerimanya. ${ }^{2}$ Bahkan silabus- silabus tersebut dirancang atas selera subyektif perancangnya dan disusun tanpa mempertimbangkan aspek- aspek pendidikan, psikologi serta budaya. ${ }^{3}$

Kurikulum seperti ini tentu saja membawa dampak yang tidak sederhana bagi pengembangan bahasaarab dikalangan non- arab. Dari sisi

${ }^{2}$ Muhammad Zaid Bakar, Al-lughoh Al-Arabiyah lada an-natiqina biha wa an natiging bighairiha. Al- majalla al- arabiyah li ad dirasat al lughawiyah, no 17, 2000, ma'had khrtoum al-dauli li al lughoh al- arabiyah, hal: 13-15.

3 Fathi 'ali yunus dan muhammad abdurrauf,Al- marji' fi ta'lim al lughoh al arabiyah li al ajanib, maktabah wahba, kairo,2003, hal: 86 
proses pendidikan bahasa, system pengajaran tersebut sadar atau tidak telah mengabaikan prinsip- prinsip pendidikan,linguistic dan psikologitiga unsure dasar yang justru harus menjadi acuan pengajaran bahasa asing. Sementara disisi out put, system tersebut mencetak anak didik dengan pencapaian bahasa yang sangat minim. Mereka pada umumnya tidak memiliki keahlian yang memadai dalam hal penggunaan bahasa baik secara lisan maupun tulisan, akibat dari metode pengajaran yang begitu focus pada tata bahasa ( nahwu-saraf ).

Kurikulum pengajaran tersebut di atas beserta dampak yang di timbulkannya, dalam motif yang lebih kurang sama, juga dijumpai dalam dunia pengajaran bahasa arab di Indonesia. Ahmad Salabi, ${ }^{4}$ Sejarawan dan pemikir Mesir, pernah mensurvei system pengajaran bahasa arab di Indonesia dan menyimpulkan bahwa kurikulum pengajaran bahasa arab di Indonesia menghadapi persoalan yang sangat serius, diantaranya adalah bahwa buku pegangan pengajaran bahasa arab yang memadai belum ada dan tersedia. Selain itu metode pengajaran yang di terapkan masih benar- benar terfokus pada tata bahasa ( qawaid) . akibat dari semua itu adalah rendahnya tingkat pencapaian bahasa arab anak Indonesia walaupun mereka telah menghabiskan waktu yang relative lama untuk mempelajarinya.

Walaupun hasil surfey Ahmad Salabi tersebut merujuk pada kondisi pengajaran bahasa arab di tanah air 20 tahun silam, namun harus di akui kondisi tersebut masih lestari sampai hari ini, paling tidak dari segi rancangan tujuan dan materi pengajaran. Dalam topic imnti kurikulum nasional 1998 yang dikeluarkan departemen agama di jelaskan bahwa pengajran bahasa arab disemua jurusan dan program study di lingkungan sekolah tinggi Agama islam bertujuan untuk mengantarkan mahasiswa mengetahui seluk beluk bahasa arab, khususnya aspek gramatikal. Untuk menunjang tujuan tersebut di tetapkan buku- buku refrensi wajib seperti : An- nahwu al- waadih, al- qiroah wa al-Kitaabah, dan jaamiu ad-duruus al-arabiyah ${ }^{5}$ Di sini tampak jelas bahwa tujuan pengajaran bahasa Arab masih terfokus pada aspek keahlian pasif berbahasa yakni penguasaan tata

${ }_{4}$ Ahmad Salabi, ta'lim al- lughah al- arabiyah lighairi al arab, maktabah an-nahdahalmisriya,( kairo, 1980),hal: 18

${ }^{5}$ Lihat; topik inti kurikulum Nasional Perguruan Tinggi Agama Islam (Fakultas Tarbiyah, Adab, Syari'ah Ushuluddin, dan Dakwa), Departemen Agama RI, Direktorat Jendral Pembinaan Kelembagaan Agama Islam, Direktorat Pembinaan Perguruaan Tinggi Agama Islam , 1998. 
bahasa (grammar), semtara keahlian mendengar (mahaarat al-istimaa'), keahlian berbicara (mahaarat al-kalaam), keahlian membaca maharat alqiroah), dan keahlian menulis mahaarat al-kitaabah) yang merupakan inti pengajaran bahasa asing modern tidak mendapat perhatian. Demikian juga dengan buku-buku yang dijadikan referensi wajib. Masih memakai kitabkitab berbahasa arab yang sesungguhnya bukan dirancang sebagai buku pegangan mengajar.

Melihat kenyataan tersebut serta mengingat dampaknya yang tidak sederhana bagi pengembangan dan penyebaran bahasa Arab di kalangan non-Arab dibenahi secara pemahaman yang mendalam tentang konsep dan system pengajaran bahasa Arab modern. Untuk itulah penelitian ini dimaksudkan untuk mengintroduksi system pengajaran bahasa Arab modern yang sebenarnya sudah lama di kembangkan di Negara-negara Arab dan beberapa Negara non-Arab. Hal ini tentu dengan tujuan agar kurikulum yang akan diketengahkan disini bisa diadopsi atau setidaknya menjadi landasan teoritis sebagi upaya perbaikan dan pengembangan kurikulum dan system pengajaran bahasa arab dikalangan non-Arab, khususnya di Indonesia

\section{B. Kurikulum Pengajaran Bahasa Arab Untuk Non-Arab}

Kurikulum pengajaran bahasa arab untuk non-Arab telah melewati proses perkembangan yang cukup panjang, baik dari aspek pemahaman kurikulum yang menjadi unsure utamanya, maupun dari aspek filosofi pengajaran bahasa arab itu sendiri sebagai salah satu bahasa asing .

Pada awal perkembangannya,kurikulum pengajaran bahasa Arab masih sangat sederhana, bahkan terlalu sederhana untuk sekedar disebut sebagai sebuah kurikulum. Hal ini karena kurikulum yang diterapkan masih sangat sederhana dan tradisional baik dari segi filisofi maupun dari segi isi dan rancangannya. Kurikulum hanya difahami sebatas kumpulan materi kebahasaan yang akan diajarkan pada anak didik, tanpa adanya factor-faktor pendukung lain yang memungkinkan materi kebahasaan itu bisa diajarkan secara efektif dan ideal. Hai ini tentu saja tidak terlepas dari kecenderungan umum dalam pemahaman dan implementasi kurikulum pengajaran dalam dunia pendidikan saat itu yang antara lain sangat kental dengan visi kognitif. 
Ketika terjadi perubahan dalam pemahaman visi, serta implementasi kurikulum dalam dunia pendidikan kurikulum pengajaran bahasa Arab pun mengalami pergeseran orientasi. Perubahan yang paling signifikan adalah terletak pada pemahaman akan esensi kurikulun dan filosofi pengajaran bahasa itu sendiri.Kurikulum kemudian dipahami tidak hanya sebatas kumpulan materi kebahasaan akan tetapi sebagai sebuah kerangka dari sebuah sistem pengajaran bahasa yang dirancang dengan visi, misi, serta komponen organisasi yang teratur. Dan bahasa kemudian tiadak hanya diajarkan sebagai sebuah nila- nilai kognitif akan tetapi juga sebagai alat komunikasi yang tidak hanya harus diketahui tapi juga dipergunakan.

Untuk memahami lebih jauh perkembangan system pengajaran bahasa arab untuk non- arab ,berikut ini akan di kupas masing- masing kecenderungan kurikulim pengajaran bahasa sebagai unsure dasar system pengajaran bahasa arab.

\section{Kurikulum Pengajaran Tradisional}

Kurikulum, sebagaimana telah di singgung di muka, telah mengalami perkembangan pemahaman dari masa kemasa. Sehingga pengertian dan batasannya juga bergeser mengikuti penggeseran pahampaham pendidikan secara umum, Secara tradisional kurikulum dipahami sebagai kumpulan informasi, kebenaran- kebenaran,serta faham- faham yang coba ditransferkan oleh lembaga sekolah kepada anak didik dengan tujuan mempersiapkan mereka untuk menjalani kehidupan serta membangun kemampuan mereka dengan mengambil manfaat dari pengalaman orang lain. ${ }^{6}$

Kurikulum dengan pemahaman seperti ini memiliki ruang lingkup yang sempit karena hanya berintikan materi atau bahan pelajaran yang diposisikansebagai satu- satunya unsure penting dalam proses belajarmengajar. Selaain itu kurikulum dengan pemahaman seperti ini juga melalui proses perancangan yang menantang karena di susun hanya berdasarkan pendapat dan pandangan para pakar dan ahli di bidang ilmu tertentu ${ }^{7}$

${ }^{6}$ Rusdi Ahmad T'aimah, ta'lim a- lughah al- arabiyah li ghairi natiqina biha: manahijuhu wa asalibuhu mansurat al- munazamat al-islamiyah li at- tarbiyah wa al 'ulum wa at- staqofah,( robat, 1989),h.59.

7 Hilmi Ahmad al-wakil dan Muhammad Amin al-mufti, al-manabij; al-mafhum, al-anast, al-usus, al-Tanzimat, Cet.2,( Makatabah al-Misriya, 1998),h. 15. 
Dari sisi bangunan dan kandungan model kurikulum seperti ini mengabaikan unsur unsur fital lain yang sangat menentukan dalam sebuah proses belajar mengajar di lembaga pendididkan, seperti; visi dan misi, metodologi teknologi dan evaluasi.

Selain itu, kurikulum model ini dalam proses perancangan mengabaikan aspek psikologis anak didik yang juga merupakan salah satu elemen penting dalam pendidikan. Materi atau bahan pelajaran yang di rancang kerap kali tidak sesuai dengan kindisi obyektif anak didik serta tidak mencerminkan kebutuhan dan tingkat kesiapan mereka.

Model kurikulum seperti ini sempat sekian lama diadopsi menjadi model kurikulum pengajaran bahasa Arab untuk non-Arab. Maka di kenal kurikulum pengajaran bahasa Arab tradisional yang salah satu karekteristik dasarnya adalah stressing yang berlebihan terhadap silabi atau materi kebahasaan dalam proses penyusunanya di samping itu, juga stressing yang berlebiham pada aspek-aspek grammer atau qawa'id dalam proses pengajaran bahasa Arab, dimana pengajaran bahasa Arab kemudian sangat identik dengan pengajaran qawa'id, dan penguasaan bahasa Arab juga diidentikan dengan penguasaan qawa'id.

Orientasi pengajaran bahasa Arab seperti ini terlepas dari kecenderungan umum pengajaran bahasa asing yang kalaitu sangat dipengaruhi oleh pengajaran bahasa Latin dan Yunani yang sangat mementingkan penguasaan grammar dan kemampuan menterjemah. Orientasi pengajaran bahasa seperti ini didasarkan pada keyakinan bahwa bahasa di bangun oleh serangkaian aturan grammar,dan oleh karenanya diyakini bahwa bahasa tidak mungkin dikuasai tanpa pemguasaan grammar. $^{8}$

Pada perkembangan selanjutnya kurikulum yang grammar -oriented ini dirasakan tidak efektif, baik dari sisi design kurikulumnya sendiri maupun efektifitasnya dalam proses penguasaan bahasa Arab. Dari segi design, bangunan kurikulum seperti ini masih sangat semput untuk menjadi acuan pengajaran bahasa Arab yang begitu kompleks. Kurikulum tersebut hanya terdiri dari satu unsure pokok yakni silabi atau materi pengajaran. Sementara unsur unsur penting lain seperti visi, metodologi dan evaluasi belum tercakup. Sedangkan dari segi out-put nya, model

\footnotetext{
${ }^{8}$ Rushdi Ahmaad Ta'lim al-lughah...., Hal 99.
} 
kurikulum seperti itu tidak memungkinkan adanya penguasaan bahasa secara sempurna dan mendalam. Hal ini karena penekanan yang berlebihan terhadap aspek gramatikal dengan sendirinya menggiring proses perolehan bahasa kepada penguasaan bahasa secara pasif dan tidak komunikatif. Kenyataan pada lembaga-lembaga pengajaran bahasa Arab di berbagai Negara yang masih mengikuti model kurikulum ini menunjukan bahwa bahaa Arab cenderung dikuasai dariaspek grammaticalnya saja. Sementara aspek komunikasi dan penggunaanya dalam kehidupan ril sangat minim. Dalam bahasa sederhana, model kurikulum seperti ini akan melahirkan ahli nahwu dan saraf namun tidak memiliki kemampuan berkimunikasi dengan bahasa Arab.

\section{Kurikulum Pengajaran Modern}

Berkat perkembangnan yang pesat dalam bidang pendidikan serta dibidang- bidang lain yang memiliki hubungan langsung atau tidak langsung dengan dunia pendidikan kemudian terjadi pergeseran dalam pemahaman kurikulum. Kurikulum kemudian bergeser pemahannya dan lebih mengacu kepada sekumpulan materi pendidikan yang di transfer oleh lembaga sekolah sehingga kepada anak didik baik di dalam maupun di luar sekolah dengan tujuan untuk membantu mereka perkembangan secara sempurna dalam segenap aspek (inteligensia, budaya, agama, social, fisik, non-fisik,serta seni) yang tercermin dalam perubahan sikap dan perilaku sesuai dengan tujuan -tujuan pendidikan yang telah di tetapkan. ${ }^{9}$

Dengan pemahaman seperti ini kurikulum, dari segi visi dan kandungannya, tidak lagi beraksentuasi pada meteri, akan tetapi kenapa anak didik itu sendiri dengan segenap aspek perkembangannya yang tidak hanya mecakup sisi inteligensia tapi juga sisi-sisi lain dalam dirinnya seperti; sisi spikologis, social, religious, dan cultural.

Pergeseran pemahan kurikulum seperti ini kemudian juga membawa penggeseran konsep kurikulum pengajaran bahasa Arab untuk non-arab, kurikulum pengajaran bahasa arab kemudian dipahami sebagai" konsep berupa proses pembekalan peserta didik dengan sejumlah materi (kebahasaan) kognitif, efektif, dan spikomotorik yang memungkinkan mereka berkimunikasi dengan bahasa Arab dan memahami budayanya tanpa pengaruh oleh bahasa mereka sendiri " ${ }^{10}$ Artinya, kurikulum

${ }^{9}$ Hilmi Ahmad al-Wakil dan Muhammad Aminal-Mufti, al-manahij..., hal 19

${ }^{10}$ Rushdi Ahmad To'ima,ta'lim al-lighah.... Hal 60 
pengajaran bahasa arab di rancang sebagai sebuah system pengajaran dan bukan sekedar materi pengajaran atau silabi. Kemudian di wujudkan tidak hanya melalui proses pembekalan bahasa secara kognitif yang menekankan pengetahuan bahasa tapi juga secara efektif dan spikomotorik yang menekankan keahlian berbahasa. Di samping itu, juga ditunjukan tidak hanya untuk menguasai bahasa secara pasif, akan tetapi secara aktif dan komuniktif sesuai dengan fungsi bahasa itu sendiri.

Kurikulum pengajaran bahasa Arab dengan keranagka pemahaman seperti ini mencangkup beberapa unsur, yakni;

a. Tujuan pengajaran. Arinya pengajaran bahasa Arab harus bertolak dan mengacu kepada tujuan dan arah yang jelas dan terkonsep. Bahasa arab harus diajarkan untuk dikuasai tidak hanya dari sisi pengetahuannya saja tapi juga keterampilan dan kemampuan menggunakanya dalam berkomunikasi

b. Silabi dan materi pengajaran. Untuk mewujudkan tujuan pengajaran bahasa Arab tidak hanya terfokus kepada aspek gramatikal (nahwu dan saraf) karena tetaapi harus mencangkup semua aspek kebahasaan dan mengacu kepada empat kemahiran dasar, yakni kemahiran mendengar (maharat al-istima'), kemahiran berbicara (maharat al-kalam), kemahiran membaca ( maharat al- qiraah), dan kemahiran menulis (maharat kitabah).

c. Metodologi pengajaran. Di samping megacu kepada silabi, pengajaran bahasa Arab juga harus diajarka melalui metodemetode tertentu, yang dipilih sesuai dengan tujuan yang telah dirumuskan dan sesuai dengan karakter materi dan suasana dan kondisi proses belajar mengajar sendiri.

d. Alat bantu teknologi. Artinya, pengajaran bahasa Arab harus didukung dengan penggunaan teknologi modern agar lebih efektif dan tidak ketinggalan zaman penggunaan sarana teknologi seperti laboratorium, computer dan jaringan internet akan memungkinkan bahasa Arab menjawab kemajuan dan tuntutan jaman.

e. Sistem Evaluasi. Sabagai sebuah proses pendidikan pengajaran bahasa arab harus memiliki sitem evaluasi terutama system testing yang standar, yang dapat mengavaluasi tingkat perolehan bahasa peserta didik dalam segala aspeknya. System evaluasi 
juga dibutuhkan karena pengajaran bahasa Arab harus berupa program yang terencana yang tentu harus dievaluasi demi kesinambungan dan pengembangannya.

Dibanding dengan konsep tradisional konsep kurikulum modern ini,baik dari sisi, proses perancangan serta visi yang melandasinya, memiliki beberapa keunggulan, antara lain;

a. Kurikulum dilihat sebagai sebuah system.

b. Kurikulum tidak hanya berisikan materi atau silabi, tapi juga visi dan misi, metodologi, teknologi dan evaluasi.

c. Memiliki pandangan yang lebih maju tentang pengajaran bahasa,dimana pengajaran bahasa dipahamitidak hanya sebatas transfer pengetahuan bahasa tapi juga pemahaman kemahira penggunann bahasa.

Menyikapi bahsa sesuai dengan fungsi dasarya, yakni sebagai alat komunikasi. konsekuensinya pengajaran bahasa harus diarahaknan untuk menguasai bahasa secara komuniktif dalam berbagai bentuknya, tidak hanya tulisan tapi jika lisan.

\section{Model- Model kurikulum Pengajaran Bahasa Arab Untuk Non- Arab}

Pengajaran bahasa arab untuk non- arab dalam perkembangannya telah mengenal beberapa model kurikulum. Walaupun sama- sama bertujuan mengajarkan bahasa arab secara efektif,kurikulim- kurikulum tersebut berbeda satu sama lain baik dari segi isi maupun visi. Hal ini dikarenakan kurikulum pengajaran bahasa arab sangat dipengaruhi oleh perkembangan pemahaman kurikulum dalam dunia pendidikan secara umum, disamping juga dipengaruhi oleh perkembangan teori kebahasaan secara umum.

Di antara model - model kurikulum yang pernah menjadi acuan pengajaran bahasa arab untuk non- arab adalah sebagai berikut.

\section{1) Al- manhaj an-nahwi ( grammatical syllabus )}

Konsep kurikulum ini didasarkan pada dua prinsip, pertama : bahasa terdiri dari sekumpulan aturan grammar, dan oleh karenanya penguasaan bahasa harus diawali oleh penguasaan kaidah- kaidah grammar. Kedua : setiap makna dapat diungkapkan dengan setruktur kalimat tertentu, dan oleh karenanya penguasaan model- model sertuktur kalimat sangat 
menentukan dalam mengumgkapkan makna ketika proses komunikasi berlangsung. ${ }^{11}$

Proses penyusuna kurikulum seperti ini berlangsung dalam tahapantahapan sebagai berikut :

a. Menetapkan makna dan model kalimat yang hendak di ajarkan

b. Menetapkan struktur dan pola kalimat yang cocok dengan makna tersebut

c. Menetapkan kaidah- kaidah grammar yang berkaitan dengan struktur dan pola kalimat tersebut

d. Penyusunan makna dan struktur kalimat serta kaidah- kaidah grammar tersebut secara sistematis dalam sebuah rumusan kurikulum.maka, apa bila makna yanh hendak di ajarkan itu dalah kalimat (اعددت درسا اعدادا جيدا), maka langkah selanjutnya adalah menentukan pola kalimat yang cocok untuk kalimat tersebut, yakni pola : فعل + فاعل + مفعول باه + مفعل مطلق + صففة , dan kemudian menentukan kaidah nahwu yang berkaitan dengan makna dan pola kalimat tersebut, yakni kaidah maf'ul mutlaq.

Dalam pengajaran kaidah grammar model kurikulum ini menerapkan metode tariqah an nahwu wa at- tarjamah (grammar translation method ). Metode yang merupakan metode paling tradisional dalam system pengajaran bahasa asing ini dalam prakteknya memberikan penekanan yang ekstra pada aspek grammar. Dalam konteks pengajaran bahasa arab untuk non- arab, metode ini bertujuan membekali anak didik kemampuan untuk memahami teks- teks arab demngan cara mengajarkan sebanyak mungkin kaidah- kaidah nahwu dan saraf dan kemampuan menterjemah.

Model kurikulum seperti ini memiliki kelemahan mendasar, antara lain ${ }^{12}$

a. Identifikasi dan analisis kalimat serta pola-polannya secara grammatical tidak dapat dijadika acuan untuk mengetahui dengan pasti makna penggunaan kalimat tersebut dengan dalamkomunikasi riil.

${ }^{11}$ Rusdi Ahmad tu'aimah, ta'lim al-lughoh al-arabiyah an-natiqin biha: manahijuhu waasalibuhu, mansurat al munazamat al- islamiyah li at- tarbiyah wa al- ulum wa as saqofah. Rabat, 1989: 99

${ }^{12}$ Rushdi Ahmad to'lim.....hal101. 
b. Untuk mengungkapkan sebuah makna tidak selalu terpukau pada pola kalimat tertentu. Satu makna dapat diungkapkan dalam pola dan struktur kalimat yang berbeda-beda, seprti contoh berikut;

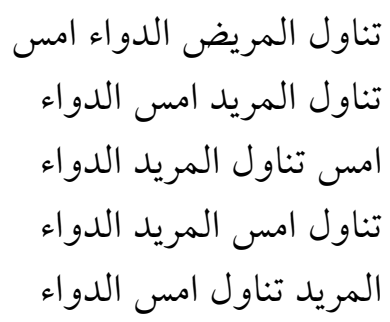

c. Model kurikulum seperti ini tidak memberikan kesempatan yang cukup untuk berkomunikasi, karena penyusunan materi atau bahan pengajaran tidak didasarkan pada situasi atau konteks yang dapat merangsang penggunaan bahasa.

d. Model kurikulum seperti ini biasanya hanya melahirkan banyak ahli tata bahasa akan tetapi tidak memiliki keterampilan menggunakan bahasa dalam komunikasi riil.

\section{2) Manhaj al-Mawaqif (Situation syllabus)}

Model kurikulum ini muncul sebagai kritik sekaligus pembenahan atas Al-manhaj An-nahwu (grammatical syllabus). Jika dalam al-manhaj an-nahwu (grammatical syllabus) materi pengajaran disusun menurut topic- topic grammar. Dalam manhaj al-mawaqif (situational syllabus) ini seperti pengajaran di susun berdasarkan situsi atau konteks komunikasi yang di rancang untuk merangsang penggunaan bahasa secara kumunikatif mempelajari struktur dan pola kalimat yang di pakai.

Model kurikulum ini didasarkan pada hakikat bahasa sebagai fenomena social yang muncul dan berkembang sebagai sarana komunikasi bagi manusia. Oleh karena iyu, setiap proses belajar mengajar bahasa yang mengacu kepada fungsi dasar bahasa sebagai alat komunikasi tersebut. Dengan kata lain, proses belajar mengajar bahasa harus dituntukan untuk penguasaan bahasa secara komunikatif. Secara praktis hal ini diwujudkan dalam bentuk satuan pelajaran yang memuat konteks komunikasi berbahasa, misalnya bahasa pelajaran tentang airport, pasar,perpustakaan, rumah sakit, dan medan-medan komunikasi lainya. 
Dalam penyampaian materi kebahasaan kurikulum ini merupakan metode at-ariqo al-mubashara ( direct method) dan metode at-ariqo assam'iya al-basariya (Audio-lingual method) yang memang muncul sebagai kritik atas metode at-tariqoh an-nahwu wa at-tarjamah. Kedua metote berangkat dari pemahaman bahwa bahasa hakikatnya adalah komunikasi lisan. Oleh karna iti keduanya sama-sama memberikan yang ekstra pada keahlian berbicara dalam pengajaran bahasa. Secara sistematis bahasa di ajarkan sebagai mana proses anak kecil mempelajari bahasa yakni di awali dengan proses mendengar, kemudian berbicara, lalu membaca dan menulis. ${ }^{13}$

Sebagaimana model kurikulum sebelumnya, kurikulum manhaj al-mawaqif (situational syllabus) juga tak luput dari kritik, diantaranya sebagai berikut: ${ }^{14}$

a. konteks dan medan komunikasi tidak bisa dibatasi, sebab kebutuhan komunikasi tiap anak didik berbeda. Sebab tema atau konteks komunikasi bisa saja cocok untuk sebagian anak didik tapi bisa jadi tidak cocok bagi sebagian yang lain.

b. komunikasi bahasa yang di ajarkan didalam kelas, walaupun mewakili keinginan peserata didik, tetap saja tersa sebagai bentuk komunikasi bahasa rekaan yang tidak sama dengan komunikasi bahasa rill diluar kelas.

c. terdapat perbedaan yang mendasar. Antara konteks pemakaian bahasa dalam kelas dengan yang sebenarnya terjadi di luar kelas konteks pemakaian bahasa dalam kelas dengan seting pasar, misalnya, sering kali hanya terfokus pada kegiatan membeli barang-barang tertentu. Padahal, pada kenyataanya konteks pemakaian bahasa juga mencangkup kegiatan menjual, atau tujuan-tujuan lain yang mendorong seseorang berada di pasar.

\section{3) Manhaj al-fikrah (national syllabus)}

Jika kurikulum manhaj an-nahwu terfokus pada bentuk dan pola-pola kalimat yang membentuk makna, dan kurikulum manhaj almawaqif pada situasi dan konteks penggunaan makna bahasa, maka model

\footnotetext{
${ }^{13}$ Muhammad 'Ali al-khuli, Asa alib Tradris al-lugha al-Arabiya,cet.3,1989, hal.22-23.

${ }^{14}$ Rusdi Ahmad To'imah, ta'lim..., hal.103.
} 
kurikulum manhaj al-fikra terfokus pada makna bahasa itu sendiri atau pada apa yang hendak di ungkapkan oleh setiap penggunaan bahasa.

Karena makna merupakan focus, maka proses penyusunan materi pengajaran menurut kurikulum ini berdasarkan atau mengacu kepada makna yang hendak di ungkapkan oleh pengguna bahasa. Oleh karna itu materi kurikulum ini secara dominan terdiri dari bentuk-bentuk makna dan rumus atau pola kalimat yang bisa di pakai untuk mengungkapkanya bentuk-bentuk makana yang hendak di ajarkan tesebut di bagi ke dalam unit-unit inti di mana masing-masing terdiri dari beberapa sub unit.unitunit inti itu antara lain: unit waktu, jumlah,tempat, dll. Masing masing unit ini meliputi beberapa sub unit, misalnya: unit waktu meliputi sub unit waktu: sekarang, hari minggu, kemarin, hari ini, besok, ....dst.

Sebagaimana model kurikulum terdahulu, kurikulum manhaj alfikra inipun menuai beberapa kritik, antara lain:

a. Penentuan serta klasifikasi makna yang menjadi dasar penyusunan materi pengajaran menurut model kurikulum ini sangat sulit dilakukan.

b. Tak ada hubungan yang pasti dan mengikat antara kaliamat dan makna. Sebuah kalimat bisa saja menngandung banyak arti bagi yang menuturkanya.

c. Proses perumusan model kurikulum seperti ini sangat sulit dan rumit.

4) Al-manhaj muta'adid al-ab'ad (Multidimensional Curriculum).

Kurikulum ini berisikan 4 (empat) aspek inti, yakni: ${ }^{15}$

a. Aspek linguistic: kurikulum ini memberikan penekanan pada penggunaan bahasa secara lancer dalam berbagai konteks komunikasi

b. Aspek budaya: kurikulum ini didasarkan pada pandangan bahawa proses penguasaan bahasa harus di iringi oleh pemahan budaya bahasa tersebut. Karena antara bahasa dan budayanya terdapat hubungan yang erat dan tak terpisahkan.

c. Aspek komunikasi: kurikulum ini secara mendasar bertujuan untuk memberikan tujuan kesempatan sebanyak mungkin untuk latihan penggunaan bahasa dalam segala konteks

${ }^{15}$ Rusdi ahmad to'imah ta'lim... hal 105. 
komonikasi. Untuk itu, materi kurikulum ini di tunjang oleh metode pengajaran, kegiatan-kegiatan, serta alat-alat bantu yang semuanya memberikan rangsangan kepada anak didik untuk menggunakan bahasa secara komunikatif.

d. Aspek umum bahasa: aspek ini dimaksudkan agar tiga aspek inti tersebut di atas dapat di terapkan dan berjalan dengan berhasil. Hal itu dengan cara membekali anak didik dengan pengetahuan umum tentang bahasa dengan harapan akan tumbuh kesadaran berbahasa di kalangan mereka. Pengetahuan umum kebahasaan antara lain meliputi: pengenalan bahasa-bahasa dunia, pengertian bahasa, dialek-dialek dalam bahasa tertentu, hubungan antara bahasa dan pikiran, peran bahasa dalam masyarakat, bilingual, asal-usul bahasa, perkembangan bahasa pada anak, hubungan bahasa dengan kepribadian, dll.

Dari empat model kurikulum tersebut, model berakhirlah yang mewakili system pengajaran bahasa arab modern. Ini karena dari segi kandunganya kurikulum multidisional lebih bernuansa dan mewakili perkembangan dunia kebahasaan itu sendiri. Selain itu, kandungan materinya tidak hanya terfokus pada aspek linguistic, akan tetapi juga pada aspek-aspek lain seperti spisikologi, budaya, dan komunikasi. Sedangakan tiga model sebelumnya lebih cocok di sebut syllabi, karena memang hanya berintikan materi-materi kebahasaan yang terfokus pada aspek grammar.

\section{Simpulan}

Dari uraian di muka ada beberapa poin yang dapat digaris bawahi sebagai kesimpulan penelitian ini, yakni :

a. Kurikulum modern pengajaran bahasa arab tidak adentik dengan silabi atau materi pengajaran bahasa arab, ada fokusnya juga tidak pada materi-materi kebahasaan yang akan diajarkan, akan tetapi pada anak didik yang akan menjalani proses penguasaan materi- materi tersebut.

b. Dalam proses penyusunannya kurikulum modern pengajaran bahasa arab tidak hanya mengacu kepada aspek linguistic, akan tetapi juga pada aspek- aspek psikologi, komunikasi,dan budaya. 
c. Dalam bangunan kurikulum modern pengajaran bahasa arab, silabi atau materi bukanlah unsure utama, melainkan hanya satu dari sekian unsure yang harus didukung unsure- unsure lainseperti visi dan misi pengajaran, metodologi pengajaran, teknologi pengajaran, serta system evaluasi.

Tujuan utama pengajaran bahasa arab menurut kurikulum modern adalah pembekalan keahlian berkomunikasi dengan bahasa arab baik lisan maupun tulisan yang didukung dengan penguasaan karakteristik dan seluk- beluk bahasa arab serta budayanya.

\section{DAFTAR PUSTAKA}

Muhammad Zaid Bakar, Al-lughoh Al- Arabiyah lada an- natiqina biha wa an natiqin bighairiha. Al- majalla al- arabiyah li ad dirasat al lughawiyah, no 17, 2000, ma' had khrtoum al- dauli li al lughoh al- arabiyah.

Fathi 'ali yunus dan muhammad abdurrauf,Al- marji' fi ta'lim al lughoh al arabiyah li al ajanib, maktabah wahba, kairo,2003.

Ahmad Salabi, ta'lim al- lughah al- arabiyah lighairi al arab, maktabah annahdahal- misriya, kairo, 1980.

Rusdi Ahmad Tu'aimah,ta'lim al lughoh al- arabiyah lighairi natiqina biha: manahijuhu wa asalibuhu,manshurat al- munazamat al- islamiyah li at- tarbiyah wa al ulum wa ath- staqofah, rabat 1989 :

Muhammad 'Ali al-khuli, Asa alib Tradris al-lugha al-Arabiya,cet.3,1989,

Hilmi Ahmad al-Wakil dan Muhammad Aminal-Mufti, al-manahi, Hilmi Ahmad al-wakil dan Muhammad Amin al-mufti, al-manabij; al-mafhum, al-anast, al-usus, al-Tanzimat, Cet.2, Makatabah alMisriya, 1998. 